\title{
Reducing Pseudoscientific and Paranormal Beliefs in University Students Through a Course in Science and Critical Thinking
}

\author{
James A. Wilson ${ }^{1}$ \\ Published online: 9 February 2018 \\ (C) The Author(s) 2018. This article is an open access publication
}

\begin{abstract}
This study measured the relationship between student's religion, gender, and propensity for fantasy thinking with the change in belief for paranormal and pseudoscientific subjects following a science and critical thinking course that directly confronted these subjects. Student pre-course endorsement of religious, paranormal, and pseudoscientific beliefs ranged from 21 to $53 \%$, with religion having the highest endorsement rate. Pre-course belief in paranormal and pseudoscientific subjects was correlated with high scores in some fantasy thinking scales and showed a gender and a religion effect with females having an $11.1 \%$ higher belief across all paranormal and pseudoscience subcategories. Students' religion, and frequency of religious service attendance, was also important with agnostic or atheist students having lower beliefs in paranormal and pseudoscience subjects compared to religious students. Students with either low religious service attendance or very high attendance had lower paranormal and pseudoscientific beliefs. Following the critical thinking course, overall beliefs in paranormal and pseudoscientific subcategories lowered 6.8-28.9\%, except for superstition, which did not significantly change. Change in belief had both a gender and religion effect with greater reductions among religious students and females.
\end{abstract}

\section{Introduction}

Paranormal and pseudoscientific beliefs are common in modern American culture (Musella 2005), often being referenced in television and movies, social media, books, and advertising. Although there is no universally agreed upon definition of paranormal and pseudoscientific subjects, they have one feature in common: they are not supported by empirical evidence and they seemingly violate the known laws of the universe. Paranormal beliefs are beliefs/entities/ processes that, if true, would violate the basic limiting principles of science (Tobacyk and

James A. Wilson

jameswilson@unomaha.edu

1 Department of Biology, University of Nebraska-Omaha, Allwine Hall 114, Omaha, NE 68182-0040, USA 
Milford 1983) and include elements of traditional religion, psychic/ESP, witchcraft, spiritualism, monsters and ghosts, and precognition. ${ }^{1}$ The paranormal also includes the domain of the so-called supernatural. This article does not make a distinction between paranormal and supernatural beliefs, except that supernatural might refer more to beings (like gods or ghosts) whereas paranormal can include both beings as well as mysterious processes like ESP or psychic healing.

Pseudoscience is any subject that is unsupported by empirical evidence and seemingly violates the known laws of science, but uses scientific language to masquerade as valid science with examples including whole body "detoxification," magnet therapy, cupping, astrology, creationism, and homeopathic medicine (Shermer 1997). In addition, pseudoscience may also include unsubstantiated fears of subjects that might warrant some genuine concern under the right conditions. For example, fear and opposition of GMOs that are based solely on the belief that they are inherently bad without evidence to back up that fear would qualify as pseudoscience, but concern over the ecological implications of genetically modified foods based on evidence would not. On the surface, it would not seem to be detrimental for someone to believe in such scientifically unsupported subjects; however, there can be a direct cost to individuals (i.e., loss of money or refusal of known medical treatments; Nahin et al. 2009) and indirect costs to society from credulous citizens.

Costs to society from credulous citizens can take different forms and propagate through many social subjects. With respect to belief in conspiracy theories, people who hold these beliefs are less likely to engage in politics (Jolley and Douglas 2014), have poor health practices (Ford et al. 2013; Gaston and Alleyne-Green 2013; Oliver and Wood 2014b), and are more likely to exhibit racist attitudes (Baer 2013; Swami 2012) and political violence (Bilewicz et al. 2013). People who subscribe to alternative medicine are less likely to vaccinate their children (Downey et al. 2010; Jones et al. 2010) or utilize treatments or medicines known to be effective (Utinans and Ancane 2014). All of these behaviors represent a socially destabilizing force, and potentially a widespread health hazard. Counteracting unsupported beliefs, by teaching critical thinking and promoting science literacy, is therefore important to the stability and health of society.

Surveys over the last 20 years have consistently shown that belief in paranormal and pseudoscientific subjects remains high among the American public (Gallup and Newport 1991; Orenstein 2002; Rice 2003). These surveys have shown that half of Americans endorse at least one conspiracy theory (Oliver and Wood 2014a) and that $73 \%$ of Americans believe in at least one paranormal subject (Stark 2012), with belief across paranormal subjects ranging from 25 to 50\% (Anderson 1998; Gallup and Newport 1991; Nisbet 1998; Wilson 2001). Of even more concern is the concomitant scientific illiteracy (unable to correctly identify basic scientific principles) that may be associated with increased paranormal and pseudoscientific beliefs (McLeish 1984). However, the relationship between science literacy and reduced paranormal and pseudoscientific beliefs remains unclear, as other studies have found no connection (Walker et al. 2002; Ryan et al. 2004).

\footnotetext{
${ }^{1}$ Belief subcategories are defined as follows: psychic/ESP includes belief in extra-sensory abilities supposedly derived from the brain including telepathy, telekinesis, clairvoyance and clairaudience, mind reading, or empathic connections to the dead; witchcraft is the ability to alter reality by performing a ritual, casting spells, or creating charms; spiritualism is a belief in communicating directly with the dead through a medium; monsters and ghosts are so-called hidden creatures in the world like bigfoot, yeti, and the Loch Ness monster and ghosts are the disembodied souls of the dead who return to Earth; and precognition is the ability to know something before it happens.
} 
Compared to the USA, European countries seem to have a lower average rate of paranormal belief; however, these beliefs can still reach high levels for certain subjects. For example, paranormal beliefs among Scandinavian youth are typically low (Harraldsson and Houtkooper 1996) with Finnish college students typically showing a disbelief in paranormal subjects and uncertainty in traditional religious beliefs (Tobacyk and Pirttilä-Backman 1992). However, approximately $15 \%$ of Swedish high school students still showed a belief in superstitions and had high (77\%) belief in precognition (Sjödin 2002). Similarly, Icelandic students showed disbelief in all paranormal subjects except precognition (Tobacyk and Milford 1983). Latvian students also showed a general disbelief in all paranormal subjects, with the exception of women having slightly higher belief in traditional religious beliefs (Utinans et al. 2015).

Several belief surveys have been developed to measure aspects of how in control a person feels about their life, how willing someone is to incorporate magical thinking, or how open someone is to accepting subjects based purely on belief. For example, how much someone feels in control of their own destiny (internally driven control) versus being at the mercy of external forces (external control; locus of control); whether magical forces influence their life (magical ideation), how completely engrossed someone becomes in fantasy situations (movies, stories, etc.; absorption); and whether a person interprets random events as pertaining directly to them (referential thinking). High scores on any of these tests have been associated with increased paranormal belief and may provide the basis for someone's natural tendency to believe in these subjects. Several studies have found a link between belief in paranormal and pseudoscientific subjects and psychological tests that measure a person's willingness to accept external forces that affect their life (Newby and Davis 2004; Hergovich et al. 2008; Sagone and De Caroli 2014). Referential thinking (Lenzenweger et al. 1997), magical ideation (Eckblad and Chapman 1983), absorption (Tellegen and Atkinson 1974), and locus of control (Rotter 1966) are all measures of the relative internal vs. external control a person has in their life. Each of these surveys measures the potential for incorporating magical thinking to explain aspects of daily life.

Why people believe in paranormal and pseudoscience is a complex subject and there are other potential factors, beyond psychological profiles, that may be linked to belief in nonempirically based subjects. For example, Lewandowsky et al. (2013) found a link between endorsement of free market economics and rejection of climate change science. This study chose to focus on more psychologically based factors as the paranormal and pseudoscientific beliefs in this study reflected an inherently unscientific basis that is likely supported by how an individual's brain perceives the world. This has been termed the "dual-process" mode of thinking where individuals may partition logical and illogical subjects in different sections of their belief space (Lindeman and Aarnio 2006).

Of interest to educators and scientists is whether individuals can overcome any propensities (as measured by the psychological tests described above) for belief in paranormal or pseudoscientific subjects. It has been suggested that exposure to critical thinking and scientific evidence may reduce these unwarranted beliefs. Critical thinking is the ability to reach a reasoned decision based on factual evidence known about a subject (Bensley 1998). In a world dominated by science and technology, critical thinking is a basic requirement. In fact, Carl Sagan once warned, "we live in a society exquisitely dependent on science and technology, in which hardly anyone knows anything about science and technology" and that this "combustible mixture of ignorance and power is going to blow up in our faces" (Sagan 1995). The importance of critical thinking skills is so valued that it is commonly included as one of the most 
important skills for teaching university students (Wyer 2009) and health professionals (Brown et al. 2001; Frye et al. 1999; Sandor et al. 1998; Scott et al. 1998). One assumption among higher education curriculum objectives is that students with welldeveloped critical thinking skills will be less likely to believe in unsupported or fraudulent subjects commonly associated with paranormal and pseudoscientific beliefs. To this end, several studies have investigated the effect of education and critical thinking on various beliefs.

Higher education has been considered as being associated with a reduction in paranormal and pseudoscientific beliefs (Peltzer 2003). Aarnio and Lindeman (2005) found that university students had fewer paranormal beliefs than vocational school students, and that the difference was largely due to the greater amount of analytical thinking that students were engaged in at the university level. Similarly, Otis and Alcock (1982) found that university professors were more skeptical of paranormal subjects than university students or members of the general public. In another study, as students learned more about psychology, their ability to distinguish between science and pseudoscience increased and subsequently their belief in the paranormal decreased (Bensley et al. 2014). Like Aarnio and Lindeman (2005), Bensley et al. (2014) found that the decrease in paranormal beliefs was associated with exposure to more analytical thinking.

Engaging in critical thinking skills, particularly in higher education coursework, can have a reducing effect on student's belief in paranormal subjects. For example, it was found that the paranormal beliefs of participants ( $>55$ years old) were reduced following a 1-week course in skeptical inquiry (Banziger 1983). Similarly, students in a course dedicated to skeptical investigation of parapsychology had a 32-45\% decrease in paranormal beliefs (McLean and Miller 2010; Manza et al. 2010). Students exposed to methods of critical thinking and evaluation of experimental design lowered their paranormal beliefs by $10 \%$ (Stark 2012), and the more scientific knowledge students had the more they rejected paranormal subjects (Bensley et al. 2014). Many of these studies measured changes in paranormal belief after taking regular courses infused with critical thinking; however, in this study, changes in students' beliefs were investigated following a course specifically designed to teach critical thinking and basic science as well as directly confronting paranormal and pseudoscientific beliefs.

Thus, it appears that the development of critical thinking skills is important in preventing acceptance of paranormal beliefs. The hypothesis tested in this study was that a semester-long course focused on teaching basic science and critical thinking skills, while simultaneously confronting paranormal and pseudoscientific subjects, would decrease beliefs in these topics. In addition, it was hypothesized that factors involved in paranormal acceptance identified by previous studies (religion, gender, and/or fantasy thinking) would affect both pre- and post-course belief in paranormal and pseudoscientific subjects. Specifically, it was assumed that students who identified themselves as more religious would not show as much decrease in paranormal beliefs as less religious students. In addition, students who were not religious would show low paranormal beliefs before class and would maintain those low beliefs during the course. Finally, following previous literature, it was expected that students scoring high on the psychological surveys (locus of control, absorption, magical ideation, and referential thinking) would also have higher initial paranormal and pseudoscientific belief scores. 


\section{Method}

\subsection{Research Subjects and Course Description}

This study recruited undergraduate students enrolled in a course on science and critical thinking at a 4-year university. Recruitment was based on student registration, participation in this study was voluntary, and no compensation was available to students involved in this study. A total of 369 students were given the initial set of questions (pre-test and psychology profiles); however, only 313 completed both pre- and post-course questions. Reasons for elimination from the dataset were primarily due to students dropping out of the course and not completing the questions or because their answers were deemed unreliable (every answer on all questions was the same). Each student in the class was given a code number to be used on surveys and assessments in order to ensure student anonymity. Students could opt out of taking part in the research if they desired.

Science and Critical Thinking is a 3-credit lecture-based course at the University of Nebraska at Omaha with a class size of 100-300 students. It is intended for non-biology majors and is populated by a diverse group of students, from freshman to seniors, majoring in many different disciplines. Science and Critical Thinking is a course that revolves around understanding the scientific methods and applying data-driven thinking to unusual subjects commonly categorized as pseudoscience or paranormal. There are many views on the nature of science (Loving 1991) and how to distinguish it from other, non-science endeavors. The course used for this study follows the basic framework outlined by Cobern and Loving (2001) as the standard account of science and uses Laudan's (1996) clarification that science is a method for separating reliable from unreliable knowledge as a base for exploring the extraordinary claims of paranormal and pseudoscientific subjects. Additionally, this course assumes that there is an objective truth/universe that is independent of human perception and that can be understood through careful investigation. This course also states that, so far, the process of science is the only process that humans have developed that gives reliable answers as to how the universe functions. However, this course also includes a discussion of other ways of obtaining knowledge, but that, unlike any other method of knowing, the scientific methods are the only ones that attempt to control for the inherent bias of humans. Following Cobern and Loving's (2001) description of science, the course in this study considered that science is naturalistic, empirically testable, descriptive, and explanatory, and assumes that the natural laws are universal in time and space (i.e., carbon on Earth is the same as carbon on Mars or Kepler 22b).

This course provides a broad introduction to the major natural processes that occur in the universe and assumes no previous knowledge of science (Table 1). First, students closely examine the scientific methods, logical reasoning and fallacies, and how their body senses and interprets the world. Second, they learn about numerous popular pseudoscientific (alternative medicine) and paranormal subjects (ghosts, cryptozoology, psychic abilities, space aliens) and critically evaluate these claims from a scientific perspective. There are numerous in-class demonstrations to illustrate in real-time problems with perception and how paranormal events are usually misunderstandings of normal phenomena. For example, students take part in several brain games where students try to follow a certain pattern (like reading the font color of a written word) but find that they cannot perform well when the written word is "Red" but the font color is blue. Students then understand how the brain prioritizes certain data (reading) above other data (color identification). In another example, the professor performs the ghost 
Table 1 Lecture topics for the Science and Critical Thinking course described in this study. Class sections are divided by a lecture exam

\begin{tabular}{ll}
\hline Class section & Lecture topic \\
\hline First & Scientific Method \\
& Pattern Recognition in the Brain \\
& Sensory Systems and Perception \\
& Critical Thinking Skills and Probability Theory \\
& Logical Fallacies \\
& Photographs and Trick Photography \\
Second & Natural Laws - Physics and Chemistry \\
& Natural Laws - Biology \\
& Near Death Experience \\
& Ghosts and the Search for the Soul \\
& ESP/Psychics \\
& Alternative Medicine/Detoxification \\
Third & Astrology \\
& Bigfoot and other "hidden creatures" \\
& Vampires \\
& UFO - Brief History of famous "sightings" \\
& UFO - Natural Phenomena typically confused with aliens \\
Fourth & Science of Life/Extra-terrestrial life requirements \\
& Scientific search of life in the Universe \\
& UFO Abduction \\
\hline
\end{tabular}

flashlight trick where a flashlight that was previously turned on is turned off and placed on the table. Without touching the flashlight, the professor asks that if there is a ghost in the room to please turn on the flashlight. Students sometimes gasp in amazement when the flashlight turns on without anyone touching it. However, the real explanation for this phenomenon is quickly given and students find out that when the plastic housing in the flashlight heats up the plastic expands and as it cools the plastic contracts. If you turn off the flashlight by twisting it so the electric contacts are barely separated, then as the plastic cools and contracts it will make contact with the battery and turn on. It is physics, not a ghost.

As a hands-on lesson in data collection, this course includes an assignment requiring students to investigate a local paranormal phenomenon and collect data to support or refute the claims related to this phenomenon. In Omaha, there is a legend of a stone staircase in a local park that supposedly no one can count the stairs up and down and get the same number of steps up as down. Students are required to count the stairs themselves, identify if they did or did not obtain the same counts, and evaluate why they may not have counted the same number up as down. In addition, students listen and write evaluations of several science-based podcasts that frequently discuss pseudoscientific and paranormal subjects from a science perspective.

There are some scholars who voice concerns over the claim that science (sometimes called "Western science" or the standard account) is the only method of obtaining reliable knowledge and that it is being applied beyond the scope of science (Haack 2007). In addition, science is sometimes branded as being elitist to the exclusion of other worldviews, most notably the traditional ecological knowledge (TEK) of indigenous peoples. This overextension of science has been given the name "scientism" and is especially concerning to science philosophers with regard to science education. Gasparatou (2017) provides an excellent discussion of how to instill the great importance of science in students and teach them how to obtain and use scientific information without glorifying science into the realm of scientism. I should note that the course in this study has learning objectives that are very similar to what Gasparatou (2017) 
suggests, specifically presenting alternative hypotheses and looking to data to find the most supported hypothesis. Cobern and Loving (2001) state that, in the education sphere, science is frequently treated in a way that diminishes other ways of knowing, like TEK. Although I agree that science is fundamentally different from other ways of knowing, that should not diminish the value of other forms of knowledge. However, science has proven repeatedly that it works and works well and is therefore highly valuable to the future of humanity as we try to solve complex, science-based problems. It is the reliability of science in providing results in conjunction with reducing or eliminating human bias that is frequently cited as the main reason that science is fundamentally different from any other way of knowing.

With respect to traditional ecological knowledge, scientists often reclassify it as ethnoscience rather than incorporating it under the umbrella of science (Cobern and Loving 2001). However, this separate classification is probably warranted. Indigenous peoples, including historic Western cultures, have all explored the world through observation with trial and error. This process has led to many instances where these cultures have discovered something that actually works, chewing on willow bark for pain relief, for example. However, it has also led to many instances where the same culture believes something works, when, in fact, it does not. The difference then between TEK through trial and error and science, and the reason for separate classification, is that indigenous knowledge almost never incorporates controls for human bias and misperception that we know occur (e.g., the placebo effect). In addition, indigenous knowledge (again, including Western cultures) is often tied to belief systems that lie outside the natural laws used by science (Cobern and Loving 2001). However, traditional knowledge can certainly be incorporated into the scientific process if that knowledge is used to frame hypotheses and then controlled experiments are performed.

Cobern and Loving (2001) also warned that science is frequently touted as solely a beneficial process, advancing humanity, when it has also had negative effects as well (industrial contamination, more efficient warfare, etc.). It would be wise to present science as a method of obtaining reliable knowledge and remember that knowledge, like any tool, can be used for the benefit or detriment of humanity. In fact, in this course, there are several examples of where science has either "gone wrong" or been misused for loathsome reasons. For example, students are taught about the development of thalidomide as an anti-nausea pregnancy drug and how a lack of drug testing led to an outbreak of birth defects in children. In addition, the course discusses historic misuses of science that are grounded in racism, like social Darwinism, and how it is the openness of the scientific method that weeds out these problems.

Finally, some academics view science as a worldview itself with its own set of presuppositions and values (Aikenhead 1996; Hansson and Lindahl 2010); whereas others view science as being largely independent of worldviews (Gauch 2009; Lacey 2009). It is important for educators to foster scientific interest in students from varying backgrounds, and educators should present examples of scientists with different worldviews. The course in this study tries to include a more multicultural view of science that includes underrepresented groups of scientists (e.g., Islamic scientist Ibn al-Haytham (Alhazen) and women like Frances Oldham Kelsey). It is important to include as wide a view of what science is because students whose worldviews conflict with the principles of science might avoid science as a subject of interest or potential career path (Hansson and Lindahl 2010). 


\subsection{Measurement Variables}

Except for collecting student demographic data, a series of four psychological tests were given to students on the first day of the course, before anything was said about the class objectives or content. These psychological tests included the Locus of Control (Rotter 1966), a measure of the relative internal vs. external control a person imparts to their life; Magical Ideation (Eckblad and Chapman 1983), a measurement of belief in magically controlled causation; Referential Thinking (Lenzenweger et al. 1997), an index of how likely an individual is to perceive unrelated events as pertaining directly to themselves; and a Tellegen Absorption Scale (Tellegen and Atkinson 1974) which includes three submeasures: absorption (complete attention to a subject/object, either real or fantasy), stability (ability to alter impulses based on the situation), and introversion (impulse resistance/expression). Each of these tests has been linked to beliefs in paranormal and/or pseudoscientific beliefs (Peltzer 2003; Swami et al. 2011; Lobato et al. 2014).

The Locus of Control test consisted of 29 two-way forced choice questions; 6 of the questions were uncounted filler questions. Each choice reflected a propensity for either internal or external control in a situation. Respondents chose which answer best fit their view of the world for the presented situation. Locus of control scores ranged from 0 (internal control) to 23 (external control). Individuals with low scores (internal control) tended to believe that their decisions are the basis for many of the consequences in their life, whereas individuals with high scores (external control) believed that events in their life are largely the consequence of luck, randomness, or destiny (Dag 1999; Newby and Davis 2004; Sagone and De Caroli 2014).

The Magical Ideation test is a measure of how willing an individual is to assign causation to an event, or series of events, which cannot have a causal relationship given the known rules of logic and reasoning (Eckblad and Chapman 1983). Examples of magical ideation include precognition, psychic/ESP, astrology, luck charms and curses, superstitions, and spirit guidance. The test consisted of 30 true/false questions relating to hypothetical situations with the potential for "magical causation" with 1 point given for each "correct" (i.e., magical ideation choice) answer. Seven of the questions were reversed in their scoring (set as false answers) to ensure respondents were adequately processing the test. Respondents scoring low (0-3) were considered skeptical, individuals who had a score of 4-15 were considered as normal (mixture of some skepticism and magical ideation), and respondents scoring $>15$ were considered to be credulous (Eckblad and Chapman 1983).

Referential thinking occurs when an individual believes that a random event is specifically related to them (i.e., strangers talking among themselves are perceived by an individual as talking about him/her). This test was designed to measure both simple referential thinking (people specifically notice, and might be critical of, the individual) and guilty referential thinking (individual believes they are being blamed for unconnected events or personal attributes; Lenzenweger et al. 1997). The test consisted of 34 true/false questions relating to various hypothetical situations where the respondent might interpret a random event as concerning them personally. For example, if someone is observed to be laughing they are perceived as laughing at the individual. Points were given for answering a question in the direction of referential thinking and neutral questions were included between scored questions. Individuals scoring high on this test would be associated with increased personalization of random events, i.e., finding meaning in meaningless patterns. 
The Tellegen Absorption scale was originally developed to identify individuals prone to hypnosis (Tellegen and Atkinson 1974). However, measurements of the test (absorption, stability, and introversion) have been associated with belief in paranormal subjects (McNally et al. 2004; Meyersburg et al. 2009). This test consisted of 15 statements that respondents agreed or disagreed with ( 1 - strongly disagree to 5-strongly agree). Because of the prominence of absorption in paranormal beliefs, 10 of the questions measured absorption, 2 measured stability, 2 introversion, and 1 neutral question was included. The absorption scale measured both reality (complete immersion in movies, books, nature, etc.) and fantasy absorption (complete immersion in daydreaming, role-playing, story-telling, etc.). Higher scores indicated a propensity for individuals to become "lost" in the event that had captured their total attention. As Tellegen and Atkinson (1974) state the event that has garnered total attention becomes amplified in the individual's mind and may lead to a feeling that the event was somehow different from normal reality This is especially true if the absorption is centered on an imaginary event, which may give some credibility to the imagined event. Stability and introversion are processes that may counteract absorption and represent the potential to keep individuals focused in reality, even if they are prone to high absorption. Therefore, high scores in stability or introversion may indicate less paranormal belief in an individual.

To measure the change in paranormal beliefs, students were given a modified version of Tobacyk's (2004). Paranormal belief scale once during the first class session before any other information was presented and again on the last day of class. The paranormal belief scale consisted of 36 questions grouped in nine subcategories (4 questions in each subcategory) of paranormal beliefs. Subcategories were the following: religion (mainstream religion), psychic/ ESP, witchcraft (spell casting, curses), superstition (good/bad luck), spiritualism (altered states, communicate with dead), monsters (bigfoot, Loch Ness monster), precognition (future telling), and space aliens. Additionally, a new subcategory, alternative medicine, was added to the Tobacyk (2004) paranormal belief survey to account for the recent prominence of "body detoxification" that has become popular in the general public. Although beliefs centering on mainstream religions (Christianity, Islam, Buddhism, Hinduism) were not included in the Science and Critical Thinking course, this category was included to identify if taking a critical thinking course would impact religious beliefs. A new subcategory, alternative medicine, was added to the Tobacyk (2004) paranormal belief survey to account for the recent prominence of body "detoxification" that has become popular in the general public. This new detox subcategory concerns the prominent belief-based idea that modern life somehow fills our bodies with undefined toxins and that periodic cleansing of those toxins through untested methods like cupping or footbaths are necessary for a holistic, healthy life. This new subcategory should not be confused with humans who are exposed to industrial contamination and actually carry a body burden of measureable contaminants.

\subsection{Data Analysis}

Psychology tests (locus of control, magical ideation, referential thinking, Tellegen absorption scale) and the Tobacyk paranormal belief scale have all been validated; however, because a new section of questions concerning detoxification was added to the paranormal belief scale, the belief scale had to be measured for reliability using Cronbach's alpha (Lobato et al. 2014). The overall reliability of the entire paranormal belief test as well as the reliability of each subcategory of questions was tested. Correlations between beliefs in paranormal subcategories were tested using Pearson product moment correlation. Percent endorsement of belief 
subcategories was calculated as the number of answers in agreement (score of 4 or 5) with the subject divided by the total number of answers.

Student background statistics (religion, grade point average, science courses) were calculated and summarized as percent values. Principle component analysis (PCA) was used to provide descriptive statistics for pre-course psychological tests and student's religion with each psychological test being one potential factor in the statistical analysis. Similarly, PCA was used to describe students' religion and their pre-course belief in each paranormal subcategory. PCA is a statistical procedure that can summarize complex relationships and present them in a graphic representation that is visually more comprehensible than textual results. Pre-course beliefs in paranormal and pseudoscientific subjects (overall and subcategory) were analyzed using ANOVA with gender and religion as main factors. In addition, pre-course beliefs were analyzed using ANOVA with gender and church attendance as factors. Finally, a multiple regression using gender, religion, and psychological test scores as possible factors was used to determine the relationship between these factors and individual belief subcategories. Significantly important factors within the multiple regression are reported with standardized beta values $(\beta)$ which represent how strongly the factor predicts belief (range from -1.0 to 1.0 ). Therefore, a $\beta$ of 0.31 would indicate a positive correlation between the two variables.

To determine whether taking a critical thinking course had any effect on student's belief in paranormal and pseudoscience subjects, the pre-course and post-course belief survey scores were compared. Two separate analyses were performed on the change in belief scores: (1) change in total belief across all subcategories combined, and (2) change in belief within each belief subcategory. Both analyses used ANOVA with gender and religion as factors and specific significant differences were identified using the least-squares means. Finally, the relationship between percent of lectures students attended (\% attendance) and change in overall paranormal and pseudoscientific belief was analyzed using linear regression. To reduce the effects of multiple false positives on $t$ test results, a Bonferroni adjustment for multiple comparisons was used where applicable. Unless otherwise noted, all data are reported as means \pm standard error, and all differences were considered significant if $\alpha=0.05$ level. This study was conducted under the auspices of the Institutional Review Board.

\section{Results}

\subsection{Students' Demographics}

Students $(n=304)$ in this study consisted of $52.7 \%$ females and $47.3 \%$ males. Most students had a grade point average of 3.00-3.49 (Fig. 1a). Students took more science classes in high school $(75.0 \%$ had 3-5 classes) compared to their university experience $(49.4 \%$ had 1-2 classes; Fig. 1b). However, many students in this study may have just begun their university career and have not yet taken their science courses. Students were self-reported as Christian (37.5\%), Catholic (25.8\%), Agnostic (14.1\%), or Atheist (10.2\%; Fig. 1c). The remainder of religious categories, Jewish $(0.3 \%)$, Buddhist $(0.6 \%)$, Muslim $(0.9 \%)$, Mormon $(0.3 \%)$, and Hindu $(0.3 \%)$, were individually too small to statistically stand alone and were thus grouped as "other." Most students attended religious services only on holidays $(37.5 \%$ ) or a few times a year (22.6\%), whereas only 14.2 and $12.1 \%$ attended religious services weekly or multiple times a week (Fig. 1d). 

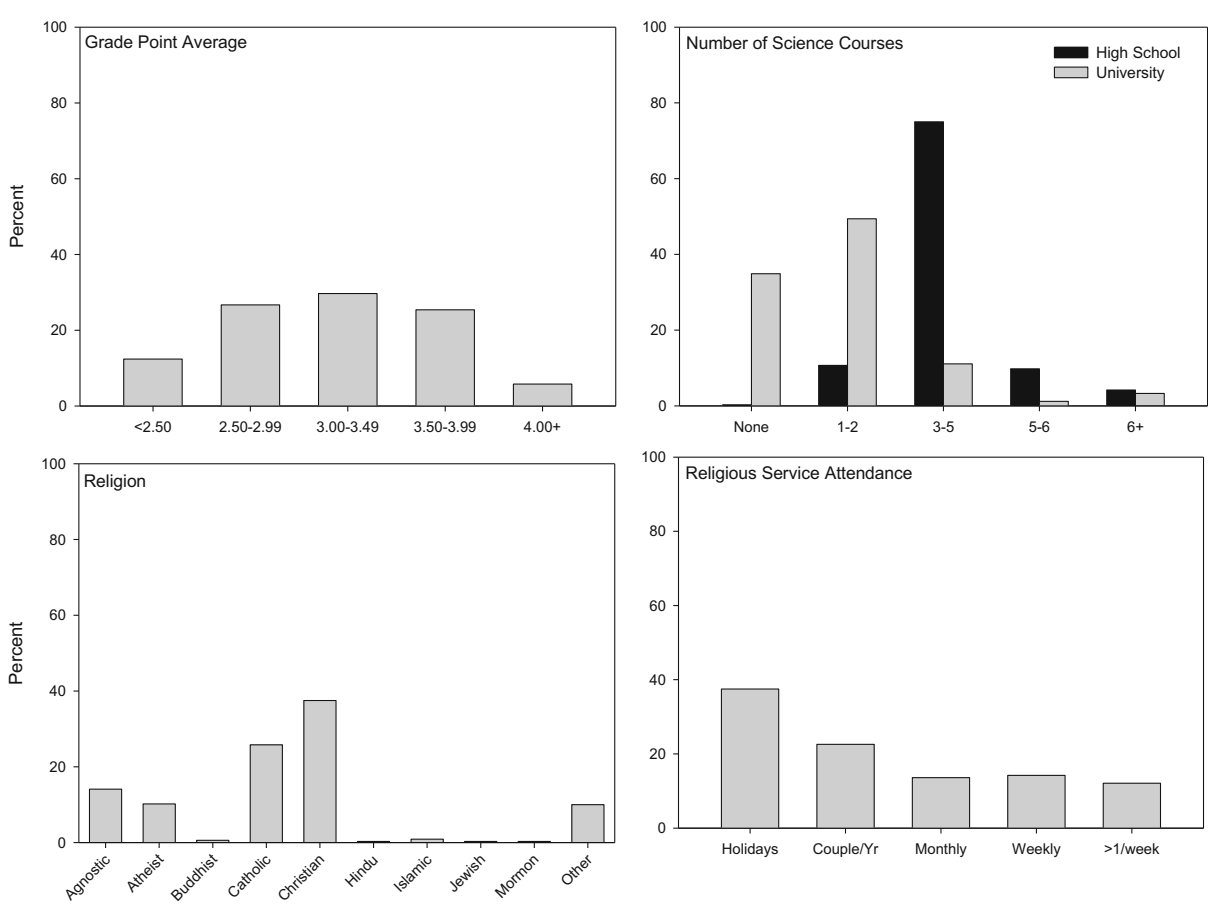

Fig. 1 Demographics of the students $(n=304)$ used as subjects in this study. All data are presented as percent of students in the study for university grade point average, number of science courses in high school and at the university level, student self-reported religion, and frequency of attendance to religious services. "Other" religion refers to all other religons not listed in the graph or people who consider themselves "spiritual but not religious"

\subsection{Belief Score Metrics}

The Cronbach's alpha for the entire Tobacyk paranormal belief scale was 0.91. The reliability of standard subcategories of paranormal belief was all above the 0.70 suggested lower limit of reliability (Nunnally and Bernstein 1994): religion (0.87), psychic powers $(0.78)$, witchcraft $(0.86)$, superstition $(0.76)$, spiritualism $(0.81)$, monsters $(0.90)$, precognition $(0.86)$, and space aliens $(0.84)$. However, the new subcategory of alternative medicine/detoxification had a reliability of 0.60 , which is in the usable, but questionable, range (Nunnally and Bernstein 1994).

Specific subcategories of paranormal and pseudoscientific belief share a common foundational belief and are therefore likely to be connected in the minds of a believer. This will be expressed as a correlation between paranormal and pseudoscientific subcategory scores. In this study, belief in psychics, witchcraft, supernatural, spiritualism, monsters, and precognition were correlated $\left(r^{2}=0.48-0.73\right)$. Religion was also correlated to a lesser degree $\left(r^{2}=0.34-0.43\right)$ to all belief subcategories except psychics, monsters, and aliens, which were weakly correlated $\left(r^{2}=0.21-0.28\right)$ with religion. The new belief subcategory, alternative medicine/detoxification, was correlated to religion (0.34), psychics (0.45), witchcraft (0.48), supernatural (0.40), and monsters (0.42) but was more correlated to spiritualism (0.57), precognition (0.52), and space aliens (0.51). 


\subsection{Beliefs Prior to the Critical Thinking Course}

Student endorsement of belief subcategories ranged from 21 to $53 \%$ with religion having the highest endorsement rate (53.0\%; Table 2). Students showed a strong belief in both God $(63.8 \%)$ and the soul existing after death $(61.9 \%)$. Alternative medicine (43.8\%), spiritualism (35.2\%), and witchcraft (32.8\%) followed religion and showed higher endorsement rates than any of the other subcategories (Table 2). All other subcategories had endorsement rates less than 30\%: precognition (25.9\%), space aliens (24.2\%), psychics (23.6\%), monsters $(21.9 \%)$, and superstition $(21.0 \%)$. Endorsement of psychic powers was low, except for the generalized belief in mind reading (38.2\%). However, there was strong endorsement of purported instances of satanic rituals and animal mutilation (41.0\%). Although most luck-based superstitions had low endorsement, students rated the existence of black magic or voodoo high $(38.3 \%)$. In addition, all spiritualist beliefs were rated high, with the possibility of speaking to the dead ranked the highest (42.1\%). Precognition was rated low (16.4 or 16.7\%) if it was associated with astrology, but was twice as high if it was presented as a vague, unexplained power to see the future (32.2 or 38.4\%). Endorsement of space aliens was relatively low (16-22\%), except for belief that the government has alien technology in a secret military base (35.7\%). Finally, the new subcategory of alternative medicine/detoxification showed high endorsement of the idea of toxins in our bodies $(75.4 \%)$ and use of herbal medicines to remove toxins from the body $(60.1 \%)$.

Pre-course belief across all paranormal and pseudoscientific categories showed both a gender and religion effect $\left(F_{9,290}=5.74, P<0.001\right)$. There was a difference in belief in paranormal and pseudoscientific subjects between student religious categories $\left(F_{4}=8.71\right.$, $P<0.001)$. The general pattern was for students who identified themselves as agnostics or atheists to have lower beliefs in paranormal and pseudoscience subjects compared to those who self-identified as religious (Catholic, Christian, Other). Across all belief subcategories, agnostic students had a significantly lower belief score than Catholic (19.5\% lower), Christian (18.8\% lower), and other religion (18.3\% lower) students. Similarly, atheist students also showed significantly lower belief scores than Catholic (21.7\% lower), Christian $(21.1 \%$ lower), and other religion (20.6\% lower) students. Agnostic students had significantly lower belief scores for psychics than Catholics (18.9\% lower), Christians (18.4\% lower), or other religions (25.8\% lower); atheists were $20.4 \%$ lower than other religions for psychics. Both agnostics and atheists had significantly lower belief scores (13.0-30.7\% lower) for witchcraft, supernatural, spiritualism, monsters, and precognition. Agnostics had lower belief in alternative medicine compared to Christians (11.5\% lower) and other religion (15.7\% lower). There was no difference in belief scores among the religious categories for aliens.

Aside from the effect of religion on pre-course beliefs, the frequency of church service attendance also had an effect on some belief categories. Total belief across all paranormal and pseudoscientific subjects combined was significantly lower $\left(F_{11,290}=2.41, P=0.007\right)$ for students who attended religious services only on major holidays compared to students who attend religious services a few times a year, monthly, or weekly. A similar relationship was observed for belief in the subcategory of supernatural phenomena $\left(F_{11,286}=2.21, P=0.01\right)$ with students who attended religious services only on major holidays having lower supernatural belief compared to students who attend religious services a few times a year, monthly, or weekly. Belief in alternative/detox medicine was the lowest for students who attended religious services only on major holidays or not at all or attended services more than once per week compared to students who attended religious services a few times per year to weekly $\left(F_{11,286}=\right.$ 
Table 2 Results of pre-class survey of paranormal and pseudoscientific beliefs using the Tobacyk (2004) belief scale. Individual questions are listed under the item column, organized by belief subcategory. Scores for each question ranged from 1 (low belief) to 5 (high belief) and the percent endorsement was calculated as the percent of respondents scoring a 4 or 5 for that question. Mean endorsement rates were calculated for each subcategory and are highlighted in italics

\begin{tabular}{ll}
\hline Item & $\begin{array}{l}\text { Mean } \\
\text { score (SE) }\end{array}$
\end{tabular} \begin{tabular}{l} 
Endorsement $(\%)$ \\
\hline
\end{tabular}

Religion

The soul continues to exist even though the body may die 57.9

There is a Devil who can inhabit the world and interact with people

$3.79 \quad 63.8$

I believe in God

3.27

3.71

There is a Heaven and Hell

3.61 57.6

Psychic powers

Some individuals are able to levitate (lift) objects through mental forces

$2.21 \quad 16.9$

Psychokinesis, the movement of objects through psychic powers, does exist

A person's thoughts can influence the movement of a physical object

Mind reading is possible

Witchcraft

Witches, who cast magical spells that affect people, do exist

Through the use of formulas and incantations, it is possible to cast spells on

There are actual cases of magical witchcraft

Numerous instances of Satanic witchcraft have been documented in the USA,

Black magic, or voodoo, really exists and can affect people

Black cats can bring bad luck, especially if they cross your path

If you break a mirror you will have bad luck

The number " 13 " is unlucky

Spiritualism

Your mind or soul can leave your body and travel (astral projection)

During altered states, such as sleep or trances, the spirit can leave the body

Reincarnation, the rebirth of a soul in another body, does occur

It is possible to communicate with the dead

Monsters

There is a large primate, commonly called Bigfoot or Sasquatch, that lives throughout North America 
Table 2 (continued)

\begin{tabular}{|c|c|c|}
\hline Item & $\begin{array}{l}\text { Mean } \\
\text { score (SE) }\end{array}$ & $\begin{array}{l}\text { Endorsement } \\
\text { rate }(\%)\end{array}$ \\
\hline
\end{tabular}

A small blood-sucking creature, called the chupacabra, kills livestock throughout 2.59 the Americas

High in the Himalayan mountains there exists a large primate-like creature called 2.65

the Yeti, or Abominable Snowman

Precognition

2.34

Astrology is a way to accurately predict the future

The horoscope accurately tells a person's future

Some psychics can accurately predict the future

Some people have an unexplained ability to predict the future

Space aliens

Ancient monuments, like the great pyramids of Egypt, could not have been made without advanced technology from aliens

People have been abducted against their will by space aliens, typically at night or

The US government has technology from space aliens housed in a secret base $\quad 3.02$ called Area 51 in Nevada

An alien spaceship crash-landed outside Roswell, New Mexico

Alternative medicine/detoxification

The modern industrial civilization that we live in exposes our bodies to many types of toxins

Traditional eastern/Asian medicine knows more about treating illness than scientific/western medicine

By eating or drinking certain herbal medicines it is possible to remove toxins from the body

Getting bone adjustments by a chiropractor can help cure the flu

$1.87, P=0.04)$. There was no relationship between religious service attendance and psychics, witchcraft, spiritualism, precognition, monsters, or space aliens.

Gender differences showed a relatively consistent pattern with females having an $11.1 \%$ higher belief across all paranormal and pseudoscience subcategories $\left(F_{1}=7.55, P=0.006\right)$. Within each paranormal and pseudoscience subcategory, beliefs among females were higher than males for precognition $(26.0 \%)$, spiritualism (19.7\%), witchcraft (18.8\%), superstition $(12.0 \%)$, psychics $(10.4 \%)$, and alternative medicine $(6.3 \%)$. There was no gender difference in the monster or alien belief subcategory.

Responses to the psychological pre-tests (Fig. 2a) and the Tobacyk belief scale (Fig. 2b) were subjected to a PCA in order to figure out which components were important in describing the religious groups in this study. No more than the first two components showed eigenvalues greater than 1, indicating that only the first two components were significant descriptors. The combination of the first two components accounted for $55.9 \%$ (pre-psychological tests) and $68.6 \%$ (pre-belief survey) of the total variance. With respect to the pre-class psychological surveys, component 1 consisted of Magical Ideation, Referential Thinking, and Absorption scores while component 2 consisted of only the Locus of Control score. Within the pre-test belief 

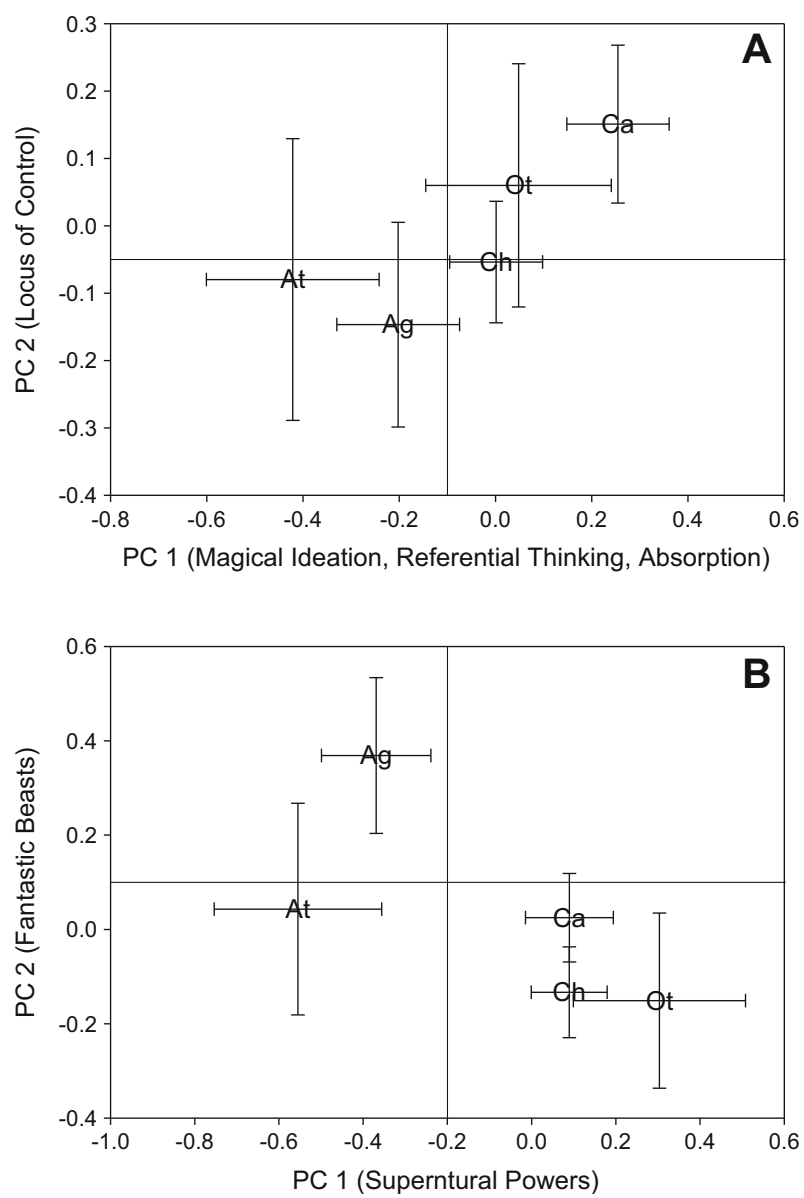

Fig. 2 Principle components analysis (PCA) for student's self-reported religion and (A) results for several belief propensity surveys (magical ideation, locus of control, referential thinking, absorption, stability, and introversion). Tests that were correlated with each of the top two components are listed on the axes. Student self-reported religion and pre-course belief in paranormal and pseudoscientific subcategories. Component 1 (PC1, $\mathrm{x}$-axis) was associated with supernatural powers (psychics, witchcraft, superstition, spiritualism, and precognition) whereas component 2 (PC2, y-axis) was associated with monsters (bigfoot, Loch Ness monster, etc.) and aliens

scale, component 1 was a combination of belief in psychics, witchcraft, supernatural, spiritualism, and precognition (i.e., supernatural powers), while component 2 consisted of belief in monsters and aliens. Religious students (Catholic, Christian, and other) clustered together for pre-course psychological surveys showing higher associations with magical thinking, referential thinking, and absorption; whereas, atheist and agnostic students scored lower. However, agnostics scored higher than atheists on the locus of control (component 2) axis. This indicates that they believed in more external control in their lives than atheists and people from all religion categories. With respect to religion and pre-class paranormal belief, atheists and agnostics showed the lowest beliefs in both supernatural powers (component 1) and monsters and aliens (component 2). Catholics showed the highest beliefs in both supernatural powers and monsters and aliens. 


\subsection{Change in Beliefs Following the Critical Thinking Course}

Looking at whether taking the course reduced belief in paranormal and pseudoscience subjects (Fig. 3), without incorporating a student's gender or religion, showed that beliefs were significantly lowered for religion $\left(T_{310}=10.27, P<0.001\right)$, psychics $\left(T_{309}=3.14, P=0.002\right)$, witchcraft $\left(T_{308}=5.68, P<0.001\right)$, spiritualism $\left(T_{309}=9.23, P<0.001\right)$, monsters $\left(T_{309}=\right.$ $9.13, P<0.001)$, precognition $\left(T_{308}=8.53, P<0.001\right)$, aliens $\left(T_{310}=13.49, P<0.001\right)$, and alternative medicine $\left(T_{310}=15.83, P<0.001\right)$. However, student belief in superstition was not significantly different after the course $\left(T_{310}=2.14, P=0.03\right)$. However, like many previous studies have shown, both gender and religion may play an important role in moderating changes in beliefs.

There was a religion and gender effect on change in belief in some subcategories of paranormal and pseudoscience belief $\left(F_{9,270}=3.02, P=0.002\right)$. The amount of change in belief by subcategory did not show a difference by students' religious affiliation with one exception: religion (Fig. 4). Within the religion subcategory there was a difference in the amount of change in the students' reported belief. Specifically, students identifying themselves as Catholic, Christian, or other religion had a greater reduction in their belief scores (24.9\% lower) for the religion subcategory $\left(F_{1,4}=4.30, P=0.002\right)$ compared to agnostics $(21.6 \%)$. Atheists did not show a significant increase or decrease in their belief in the religion subcategory.

This study found limited differences in the post-course change in belief between male and female students. The only subcategories that showed a gender effect in post-course change in belief was witchcraft $\left(F_{1}=4.85, P=0.03\right)$ and precognition $\left(F_{1}=9.30, P=0.003\right)$, with females showing a greater decrease in belief compared to males.

Multiple linear regressions were used to determine whether any psychological test scores were associated with changes in belief following the critical thinking course. The regression model for change in belief scores across all combined belief categories (i.e., total paranormal belief, no subcategories) showed a significant difference from the null hypothesis of no relationship

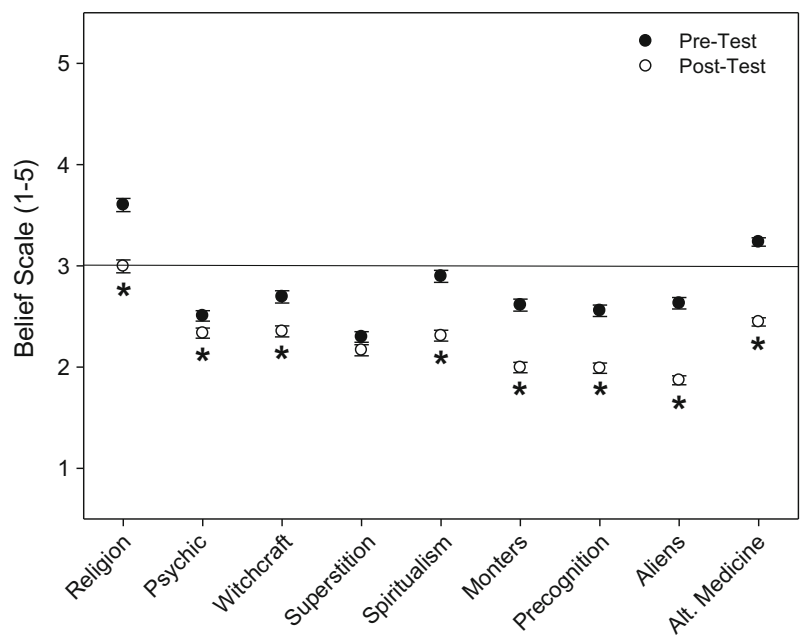

Fig. 3 Change in student's self-reported belief in paranormal and pseudoscientific subcategories after taking a course specifically designed to teach science and critical thinking and debunk unsupported paranormal and pseudoscientific subjects. Significant differences between pre-course and post-course survey scores are shown with an asterisk. Survey scores ranged from 1 (low belief) to 5 (high belief) 


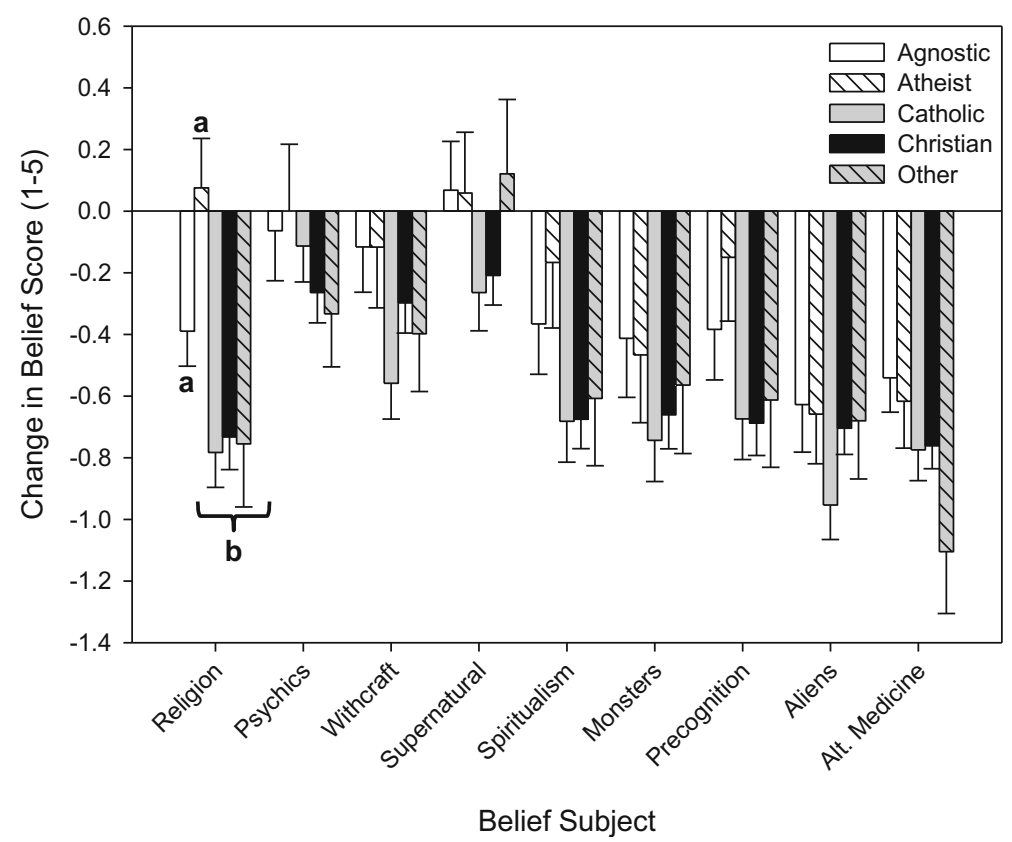

Fig. 4 Change in student's self-reported belief in paranormal and pseudoscientific subcategories after taking a course specifically designed to teach science and critical thinking and debunk unsupported paranormal and pseudoscientific subjects separated by student's religion. Significant differences in the change in pre-course and post-course survey scores are indicated with different letters. No distinguishing marker indicates values that are not significantly different

$\left(F_{8,290}=6.03, P<0.001\right)$. However, the only psychological test that was significantly associated with the total belief model was magical ideation $\left(T_{1}=-2.88, P=0.004\right)$.

When individual subcategories of belief (religion, psychics, witchcraft, etc.) were analyzed independently, all models relating belief subcategory to gender, religion, or psychological test were significantly different than the null hypothesis. However, several differences were observed regarding which variables were associated with students' change in belief within each individual belief subcategory (Table 3). Change in religious beliefs was associated with a student's religion; change in psychic belief was associated with magical ideation; witchcraft was associated with gender, magical ideation, and absorption; superstition was associated with gender and magical ideation; spiritualism with gender, magical ideation, and absorption; monsters with locus of control and referential thinking; precognition with gender and magical ideation; aliens with magical ideation, referential thinking, and absorption; and alternative medicine associated with magical ideation and absorption. Finally, lecture attendance was not significantly related $\left(F_{1,281}=0.19, P=0.66\right)$ to the observed reduction in total paranormal and pseudoscientific beliefs following the course.

\section{Discussion}

\subsection{The Effect of a Critical Thinking Course on Belief}

This study shows that taking a course in science and critical thinking, which also directly confronts paranormal and pseudoscientific beliefs, can reduce students' belief in paranormal 
Table 3 Model statistics and significant parameters (model coefficients) associated with the multiple regression model for pre-course belief in paranormal and pseudoscientific subcategories

\begin{tabular}{lll}
\hline Belief subcategory & Model statistics & Significant parameters \\
\hline Religion & $F_{8,270}=3.21, P=0.002$ & Student religion \\
Psychics & $F_{8,269}=4.69, P<0.0001$ & Magical ideation \\
Witchcraft & $F_{8,277}=6.62, P<0.0001$ & Sex, magical ideation, absorption \\
Superstition & $F_{8,270}=3.11, P=0.002$ & Sex, magical ideation \\
Spiritualism & $F_{8,269}=8.00, P<0.0001$ & Sex, magical ideation, absorption \\
Monsters & $F_{8,269}=4.67, P<0.0001$ & Locus of control, referential thinking \\
Precognition & $F_{8,269}=9.54, P<0.0001$ & Sex, magical ideation \\
Aliens & $F_{8,270}=7.55, P<0.0001$ & Magical ideation, referential thinking, absorption \\
Alternative medicine & $F_{8,270}=4.97, P<0.0001$ & Magical ideation, absorption \\
\hline
\end{tabular}

and pseudoscientific subjects. Specifically, the overall reduction in belief scores for each subcategory was as follows: religion $(16.8 \%)$, psychics $(6.8 \%)$, witchcraft $(12.7 \%)$, superstition $(5.7 \%)$, spiritualism $(20.2 \%)$, monsters $(23.6 \%)$, precognition $(22.2 \%)$, aliens $(28.9 \%)$, and alternative medicine (24.4\%). It should be noted that although there was a decrease in belief in the alternative medicine/detox subcategory, that category did not score well for Cronbach's alpha reliability and should therefore be considered with caution.

Previous studies have also found that exposing students to critical thinking methods and correcting misconceptions about science can lead to decreased belief in non-empirical subjects such as conspiracy theories, paranormal subjects, and pseudoscience (Bensley et al. 2014). For example, belief in conspiracy theories (Swami et al. 2014) and paranormal subjects (Aarnio and Lindeman 2005) was found to be negatively associated with thinking styles that included critical thinking and being open-minded to alternatives, and to be positively associated with intuition-based thinking. Even simply exposing people to words associated with the critical thinking process can have a reduction on belief in conspiracy theories compared to those who were shown random words (Swami et al. 2014). In effect, it seems that priming the brain to think critically lowers belief in non-logical subjects.

Additional research has found that taking a critical thinking class in psychology resulted in a 30-32\% reduction in belief in paranormal phenomena (McLean and Miller 2010; Burke et al. 2014). Similarly, students taking a research methods course showed a $10 \%$ reduction in paranormal beliefs following the course (Stark 2012). Specific subjects the belief in which was decreased were the following: psychic ability, witchcraft, spiritualism, and precognition. Furthermore, students exposed to a class that directly confronted paranormal phenomena in the context of known science reduced their belief in the paranormal over the course of the semester (Manza et al. 2010).

Critical thinking is a skill that requires training and practice to develop. For example, as students progressed through a psychology program, their ability to distinguish factual science from pseudoscience increased and their belief in paranormal and pseudoscientific subjects decreased (Bensley et al. 2014). Similarly, students in the sciences tend to follow a curriculum that is based on critical thinking and therefore it is not surprising that students in the sciences had lower belief in paranormal subjects (Brigstock 2003). Likewise, students in philosophy, psychology, and architecture had the lowest paranormal beliefs, whereas business, theology, and education had the highest (Aarnio and Lindeman 2005).

This study was limited in its ability to apply to student belief as a whole because it lacks a comparison group, or proper control. In addition, the location of the study, Nebraska, is 
considerably more homogeneous than many other locations in the USA. The lack of student diversity may create problems with generalizing the results to a larger student population. However, even with these limitations, the results from this study match those of many other studies, including those from Europe and across the USA.

\subsection{The Effect of Students' Religion on Belief}

In this study, there was no effect of religion on the reduction of belief for most of the subcategories; however, within the religion subcategory, students identifying themselves as Catholic, Christian, or Other had a greater reduction in their religious belief compared to atheist or agnostic students. The students in this study were predominantly Christian and Catholic, with non-believers (agnostic and atheist) being the second largest group. Not surprisingly then, on the pre-course belief survey, the religion belief subcategory had the highest endorsement rating (57.9\%). As it was expected, Catholics tended to score the highest on total paranormal belief followed by Christians and other religions, with agnostics and atheists having the lowest levels of pre-course paranormal belief.

The relation between religion and paranormal belief is complex, with religion being both a catalyst for and against paranormal beliefs. Eder et al. (2011) found a significant correlation between traditional religious beliefs and belief in paranormal subjects, suggesting that, once a person believes in one supernatural subject (religion), it can be open to beliefs in other paranormal subjects (Tobacyk and Milford 1983). For example, Catholics, whose religion includes more supernatural beliefs than Protestants, exhibit higher belief in paranormal subjects (Duncan et al. 1992; Orenstein 2002) and report 30\% more paranormal experiences than Protestants (Mencken et al. 2008). Religious "nones," in contrast, reported 22\% fewer paranormal experiences in their life (Mencken et al. 2008). Religious "nones" are people who choose the "none" box when asked about their religious affiliation. This group includes individuals who have made a conscious decision not to be affiliated with any organized religion and includes a wide spectrum of beliefs (i.e., atheist, agnostic, and spiritual but not religious). This may be because people of religious faith subscribe to a worldview that, by definition, includes supernatural events and beings, whereas atheists and agnostics have a materialistic view of the world, rejecting non-empirical explanations (Mencken et al. 2009). On the spectrum of belief, this tends to make religious people and paranormal believers more closely related to each other than atheists/agnostics are to either religious people or paranormal believers. This pattern was also observed in this study, where atheist and agnostic students grouped closer together with respect to their pre-course beliefs compared to religious students (Fig. 2a). Because of their already low belief scores, atheists and agnostics did not show the same amount of reduction in belief due to taking the critical thinking course in this study.

Religion can also serve to reduce belief in paranormal subjects; specifically, paranormal belief is reduced in people who attend religious services frequently. For example, Christians who attend church regularly report fewer paranormal experiences (Mencken et al. 2008). Similarly, Christians whose beliefs are considered moderate or liberal show higher beliefs in paranormal subjects compared to evangelical or fundamentalist Christians (Baker and Draper 2010). For highly religious people, the reduction in non-religious paranormal subjects is a result of those subjects being frowned upon by the church establishment (Mencken et al. 2008; Orenstein 2002; McKinnon 2003). This is thought to be an expression of social control and has been termed the Deviance/Marginalization Hypothesis, where individuals belonging to the group in 
power are less likely to accept non-traditional paranormal beliefs because those beliefs may ostracize them from the conventional group (Mencken et al. 2009).

In this study, the effect of frequency of attending religious services on belief in paranormal and pseudoscientific subjects supports the Deviance/Marginal Hypothesis. Students who attend religious services somewhat frequently, but not weekly or more than once per week, tended to report higher paranormal beliefs. These students may have attended church enough to expose themselves to supernatural ideas, but not enough to be affected by the social control of the marginalization hypothesis. Students who either never attended religious services (typically atheists and agnostics), or attended them weekly or more than once per week (strongly religious), typically had lower paranormal belief scores.

Although the critical thinking course that students took in this study did not specifically refer to religious beliefs, there was a significant reduction in students' religious beliefs. This might indicate that being exposed to empirically driven thinking leaks into personal beliefs, even when religion is not directly discussed. Science education has been shown to be an effective counterbalance to paranormal beliefs (Martin 1994; Martin-Hansen 2008). Unfortunately, scientific reasoning does not typically develop until middle childhood whereas nonscientific beliefs (fantasy, paranormal, or religion) are cultivated earlier in childhood (Braswell et al. 2011). Although parents report that learning science is more important than learning about religion, Braswell et al. (2011) found that scientific encouragement by parents was negatively correlated with religious encouragement. This suggests that although many parents may feel that learning science is important, in homes with higher religious beliefs, science education may not be promoted. In these households, children may not be exposed to scientific thinking until much later in life, potentially not until entering a university.

In addition to how frequently students attend religious services, higher education may be expected to alter religious beliefs. However, with respect to religious belief as a whole, college education has been shown to have little effect on overall religious belief levels. However, college exposure can loosen certain aspects of religious dogma (Reimer 2010) and reduce belief in the supernatural portions of a religion (i.e., creation myths, heaven/hell, angels/ demons-Rice 2003; Baker 2008; Eder et al. 2011). Students raised in non-evangelical religious households are most likely to see their religious beliefs decrease, especially within the supernatural religious beliefs (e.g., miracles), when exposed to empirical-based thinking at the university level (Hill 2011). If a student is influenced by critical thinking, the pattern of reduction in religious belief with exposure to higher education can continue throughout higher education. In fact, university professors, especially in the sciences, tend to be less religious and make more empirically based arguments than the general public (Gross and Simmons 2007, 2009).

Some academics believe that science and religion are incompatible (Mahner and Bunge 1996), whereas others see them as operating in separate spheres of knowledge (i.e., separate magisteria; Gould 1997). Most religions include a definition of reality that is beyond the scope of a naturalistic universe (Reiss 2009) and this may lead to conflict with science the tenets of which discount any supernatural explanations (Gauch 2009). Glennan (2009) took the stance that science and religion may be in conflict depending on how religion is viewed by its practitioners. He suggested that the conflict between science and religion will occur when religious views necessitate that well-established scientific facts be untrue (e.g., creationism discounting evolution). However, if religion is viewed as more of a personal worldview that also includes scientific facts then little to no conflict should occur. People with this 
worldview often believe God began the universe, set up all the laws of the universe, and then let the universe evolve as described by science.

Although the course reported in this study almost never referred to religion, I personally take a similar view with Glennan (2009), that the amount of conflict between religion and science depends on the definition of religion. In fact, the only time that religious beliefs were mentioned in the course was when the Second Law of Thermodynamics was discussed. During this time, we discuss how creationists misrepresent the Second Law of Thermodynamics by leaving off the all-important phrase "in a closed system." I feel that science educators should not directly confront religious beliefs, unless those beliefs require students to actively dismiss well-established scientific facts through adherence to belief only. In that case, it is important to push back against such dogmatic scientific illiteracy.

The course in this study was developed to counter unchecked belief in subjects for which there is typically little to no evidence and which seemingly violate the known laws of the universe. Although many religions often incorporate paranormal, and possibly pseudoscientific subjects, this study, and the course it was based on, took the term "religion" to refer to established, mainstream religion and its beliefs. One could make the case that there is little to no difference between beliefs in religion, the paranormal, or pseudoscience but this study separated religion based on widespread social acceptance and the political and social problems that could arise from directly confronting religious beliefs in the classroom.

If, as Glennan (2009) suggested, religion does not attack established scientific facts or require that scientific facts be untrue then it should not necessarily be the goal of science educators to reduce religious belief. However, as the results of this study show, reductions in religious belief may occur in some students as a byproduct of critically examining belief-based subjects, such as the paranormal and pseudoscience. Unfortunately, this study only measured changes in belief, including some religious beliefs, immediately following the course. It would be more informative to know whether those reductions in belief were maintained in the future (e.g., 1 year after the course) or if belief returned to pre-course levels shortly after the course was completed. Sadly, the limitations of student anonymity placed on this study by the Institutional Review Board prevent these data from being collected.

The results of this study did show an effect of religion on both student's initial belief level and their willingness to change their beliefs. This is an important finding given that relatively little empirical research has been done on the link between science and religion (Fulljames et al. 1991). They found evidence that people's worldview may affect how likely they are to develop an interest in science. Specifically, within adolescents, they found a negative correlation between Christianity, especially if that incorporates creationism, and interest in science. Conversely, they found that adolescents who have not been exposed to religion in their childhood are most likely to adopt a view of science that has been called "scientism." These adolescents were also likely to view Christianity as necessarily being associated with creationism. Clearly the relationship between religion, or belief in general, and science is complex and requires much more study to effectively promote science literacy in such a diverse population.

\subsection{The Effect of Students' Gender on Belief}

Data for a gender bias on belief in the paranormal is mixed, with some studies showing females having higher levels of belief in the paranormal (Dag 1999; Aarnio and Lindeman 2005; Mencken et al. 2008, 2009) while others found no difference in belief between males 
and females (Peltzer 2003). This study also found evidence that females had higher beliefs across total paranormal and pseudoscientific categories, and specifically in precognition, spiritualism, witchcraft, superstition, psychics, and alternative/detox medicine. Females in this study did not have higher beliefs in aliens than men. This result is similar to Aarnio and Lindeman (2005) who found that men actually had a higher belief in aliens, and who suggested that women show a more intuitive thinking processes than men and that intuitive thinking has been associated with increased belief in non-empirical subjects (Swami et al. 2014).

\subsection{Student's Propensity for Belief}

Belief in paranormal and pseudoscientific subjects is common in modern society and numerous studies have attempted to explain why these beliefs persist even when our world is largely influenced by science and technology. Several psychological measures are correlated with increased belief in the paranormal (Hergovich et al. 2008; Swami et al. 2011), including views of external control (Newby and Davis 2004), magical ideation and referential thinking (Eckblad and Chapman 1983; Lenzenweger et al. 1997), and introversion (i.e., absorption; Tellegen and Atkinson 1974; Lobato et al. 2014). This study also found an association between these psychological measurements and students' pre-course paranormal and pseudoscientific beliefs. Specifically, magical ideation and absorption were the most prominent psychological factors in predicting paranormal and pseudoscientific beliefs (psychic, witchcraft, superstition, spiritualism, precognition, aliens, and alternative medicine) with referential thinking (monsters, aliens) and locus of control (monsters) also being important predictors.

The most supported hypothesis for how people can maintain paranormal beliefs is through a dual-process mode of thinking where people use both an intuitive, or gestalt, mode of thinking as well as an analytical/logical mode of thinking (Lindeman and Aarnio 2006). According to this hypothesis, paranormal beliefs and empirical ideas may occupy distinct locations within a person's mental belief space. During our development as children, the intuitive pathway predominates, and it is joined by the analytical pathway as we enter adolescence (Sagone and De Caroli 2014). However, once in adulthood, some people may utilize the intuitive pathway more than others leading to an increase in paranormal beliefs (Lindeman and Aarnio 2006). Evidence of this dual-process thinking was found when comparing socially accepted beliefs (mainstream religion) to fringe beliefs (paranormal; Francis et al. 2010). Conventional Christian belief was associated with lower psychoticism scores and higher social conformity (lie scale scores), whereas belief in the paranormal was associated with higher psychoticism and lower social conformity (Francis et al. 2010).

Contrary to what might be expected, previous research has shown that belief in paranormal or pseudoscientific subjects is not related to how much scientific knowledge a person has (Lindeman and Saher 2007). Under the dual-process hypothesis for belief acceptance, people who have a holistic worldview (i.e., see all the components of the world as an interconnected "organism") should have stronger belief in paranormal and pseudoscience. Several studies have shown that specific traits (emotional instability; (Wiseman and Watt 2004), or life events (world instability; Padgett and Jorgenson 1982) lead to increased belief as a method of obtaining control over the uncertainties of life (Irwin 2000). Lindeman and Aarnio (2006) provided evidence that paranormal and pseudoscientific beliefs follow the dual-process mode of thinking. They suggested that many of these beliefs may be tied to a single belief category that they call the "magico-religious belief." Lindeman and Aarnio (2006) found that magicoreligious belief was associated with measures of emotional instability; however, unlike 
previous studies, they found the contribution to be rather weak. What was important in increasing magico-religious beliefs was the role intuitive thinking played in a person's life, in other words, how prominent was the holistic worldview in their thinking. Lindeman and Aarnio (2006) suggested that, in some people, there is a tendency towards a general belief in paranormal or pseudoscience that may develop into specific beliefs. They also suggested that, although they found evidence for a magico-religious category of belief, other major categories of belief may have different factors associated with belief.

There has been a robust debate about the link between science, religion, and worldviews, specifically what is the nature of science (Woodcock 2014), whether science has a worldview (Matthews 2009; Irzik and Nola 2009), or whether it is worldview-independent (Gauch 2009), as well as whether a discussion of how the scientific method contrasts with differing worldviews, especially those from religion, should be included in science education (Moreira-dos-Santos and El-Hani 2017). The course in this study discusses several different worldviews concerning the nature of truth, but ultimately takes the perspective expressed by Cordero (2009), that science has a direction with respect to worldviews and that direction is largely naturalistic. The naturalistic and empirically based worldview taken by the course in this study is in direct conflict with students whose worldviews fall into the intuitive, dual-process pattern described by Lindeman and Aarnio (2006) above. In fact, at the heart of the development of this course was an attempt to provide students with scientific evidence that would directly contradict many paranormal and pseudoscientific subjects and the worldviews associated with those beliefs. It is not the goal of the course in this study to change someone's worldview, but rather to provide a view that, if something is real and actually works, there will be empirical evidence to support that subject. Under the context of the dual-process pattern, this course attempts to bolster the logical side while providing caution about the mistakes the intuitive side can make.

The amount of external control, as measured by Locus of Control, someone feels is in their life is related to paranormal and pseudoscientific beliefs. Locus of Control scores have been correlated with all subsections of the Tobycyk Paranormal Belief Scale (Dag 1999). In addition, Newby and Davis (2004) found a link between Locus of Control and New Age paranormal beliefs (reincarnation, astrology, precognition, and witchcraft) with people exhibiting higher views of external control having higher beliefs in these subjects. Similarly, people who report being abducted by aliens score high on tests of fantasy proneness, psychological absorption and childhood imaginings, and introversion (Parnell 1988; Parnell and Sprinkle 1990; Swami et al. 2011). Sharps et al. (2010) also found that increased paranormal belief was associated with increased dissociative thinking (lower analytical or fact-based thinking processes and higher intuitive or gestalt thinking). Specifically, with respect to subcategories of the revised paranormal belief scale, dissociation was correlated with belief in bigfoot, aliens, and ghosts. Belief in superstition among adolescents was positively correlated to views of external control and negatively correlated with internal control in the Locus of Control test (Sagone and De Caroli 2014).

\subsection{Conclusion}

Critical thinking as a skill requires development, cultivation, and practice to have maximal impact on someone's belief in paranormal events and pseudoscience. Bensley 
et al. (2014) suggested that students do not have the critical thinking skills or a skeptical attitude necessary to verify facts in their daily life, and that exposing students to critical thinking will increase these traits. As a result, courses that simultaneously teach critical thinking and directly refute misinformation and myths are highly successful at lowering belief in paranormal and pseudoscientific subjects (Guzzetti 2000; Kowalski and Taylor 2009; Braasch et al. 2013; Bensley et al. 2014). Teaching critical thinking skills provides students with the tools necessary to question and investigate claims in relation to known facts whereas direct refutation of unsubstantiated subjects gives students a model of how to evaluate and confront false claims. The results of this study show that having a course that simultaneously teaches critical thinking and the scientific method with refutation of subjects that either have no empirical support, or must violate known laws of the universe to exist, can lead to decreases in paranormal and pseudoscientific beliefs. What was surprising was that belief in mainstream religion also decreased even though religion was specifically avoided as a subject in the course. Additionally, no relationship between attendance in lecture and change in belief was found suggesting that belief in paranormal and pseudoscientific subjects decreased due to exposure to the subjects, either by attending class or just studying the material for exams. This is supported by Swami et al. (2014) who found a reduction in belief simply by priming subjects for rational reasoning by showing subjects words related to an analytical thinking process (i.e., "analyze," "reason," "ponder," "think," or "rational") compared to showing subjects random words. However, courses that have both a critical thinking component and a refutational component, as the course in this study did, are superior (Bensley et al. 2014).

Courses that teach and promote critical thinking skills seem to be an important instrument in preparing students for life in a science-based society. Critical thinking will help students understand the science in their daily life as well as reduce the potential for believing in unfounded subjects like the paranormal and pseudoscience. Courses specifically designed to increase critical thinking and to confront unfounded claims have shown promise in reducing beliefs in paranormal and pseudoscientific subjects (Kane et al. 2010; Franz and Green 2013; McLaughlin and McGill 2017). With respect to history courses, students in classes with higher critical thinking (e.g., honors classes) showed more reduction in unfounded beliefs compared to students in normal history classes (McLaughlin and McGill 2017). However, McLaughlin and McGill (2017) also found that the effectiveness of a course involving critical thinking was highly dependent on a student's background. Students in the honors class had higher scientific knowledge indicating that students who place into honors courses were more likely to seek out evidence-based subjects and would therefore be less likely to believe in paranormal and pseudoscientific subjects in the first place. This study also found that a course that incorporates both critical thinking and debunking of unfounded claims can effectively reduce belief in the paranormal and pseudoscience. This may be especially important in people who rely more heavily on intuitive thinking and are therefore more prone to belief in unfounded claims (Lindeman and Aarnio 2006). Building critical thinking skills and confronting unfounded claims may be more important than ever as social media allows totally unsubstantiated claims, fake news stories, and paranormal subjects to be so easily spread through our society. 


\section{Compliance with ethical standards}

Conflict of interest The author reports no conflict of interest.

Open Access This article is distributed under the terms of the Creative Commons Attribution 4.0 International License (http://creativecommons.org/licenses/by/4.0/), which permits unrestricted use, distribution, and reproduction in any medium, provided you give appropriate credit to the original author(s) and the source, provide a link to the Creative Commons license, and indicate if changes were made.

\section{References}

Aarnio, K., \& Lindeman, M. (2005). Paranormal beliefs, education, and thinking styles. Personality and Individual Differences, 39, 1227-1236.

Aikenhead, G. S. (1996). Science education: border crossing into the subculture of science. Science \& Education, 27, 1-52.

Anderson, W. R. (1998). Why would people not believe weird things? The Skeptical Inquirer, 22, 42-45.

Baer, M. D. (2013). An enemy old and new: the Dönme, anti-Semitism, and conspiracy theories in the Ottoman Empire and the Turkish Republic. Jewish Quarterly Review, 103, 523-555.

Baker, J. O. (2008). Who believes in religious evil? An investigation of sociological patterns of belief in Satan, hell, and demons. Review of Religious Research, 50, 206-220.

Baker, J. O., \& Draper, S. (2010). Diverse supernatural portfolios: certitude, exclusivity, and the curvilinear relationship between religiosity and paranormal beliefs. Journal for the Scientific Study of Religion, 49, 413424.

Banziger, G. (1983). Normalizing the paranormal: short-term and long-term change in belief in the paranormal among older learners during a short course. Teaching of Psychology, 10, 212-214.

Bensley, D. A. (1998). Critical thinking in psychology: a unified skills approach. Pacific Grove: CA. Brooks/ Cole Publishing 269pp.

Bensley, D. A., Lilienfeld, S. O., \& Powell, L. A. (2014). A new measure of psychological misconceptions: relations with academic background, critical thinking, and acceptance of paranormal and pseudoscientific claims. Learning and Individual Differences, 36, 9-18.

Bilewicz, M., Winiewski, M., Kofta, M., \& Wójcik, A. (2013). Harmful ideas: the structure and consequences of anti-Semitic beliefs in Poland. Political Psychology, 34, 821-839.

Braasch, J. L., Golden, S. R., \& Wiley, J. (2013). The influence of text and reader characteristics on learning from refutations in science texts. Journal of Educational Psychology, 105, 561-578.

Braswell, G. S., Rosengren, K. S., \& Berenbaum, H. (2011). Gravity, God and ghosts? Parents' beliefs in science, religion, and the paranormal and the encouragement of beliefs in their children. International Journal of Behavioral Development

Brigstock, M. (2003). Paranormal beliefs among science students. Australasian Science, 24, 33-35.

Brown, J. M., Alverson, E. M., \& Pepa, C. A. (2001). The influence of a baccalaureate program on traditional, RN-BSN, and accelerated student's critical thinking abilities. Holistic Nursing Practice, 15, 4-8.

Burke, B. L., Sears, S. R., Kraus, S., \& Roberts-Cady, S. (2014). Critical analysis: a comparison of critical thinking changes in psychology and philosophy classes. Teaching of Psychology, 41, 28-36.

Cobern, W. W., \& Loving, C. C. (2001). Defining "science" in a multicultural world: implications for science education. Science \& Education, 85, 50-67.

Cordero, A. (2009). Contemporary science and worldview-making. Science \& Education, 18, 747-764.

Dag, I. (1999). The relationships among paranormal beliefs, locus of control and psychopathology in a Turkish college sample. Personality and Individual Differences, 26, 723-737.

Downey, L., Tyree, P. T., Huebner, C. E., \& Lafferty, W. E. (2010). Pediatric vaccination and vaccine-preventable disease acquisition: associations with care by complementary and alternative medicine providers. Maternal and Child Health Journal, 14, 922-930.

Duncan, D. F., Donnelly, J. W., \& Nicholson, T. (1992). Belief in the paranormal and religious belief among American college students. Psychological Reports, 70, 15-18.

Eckblad, M., \& Chapman, L. J. (1983). Magical ideation as an indicator of schizotypy. Journal of Consulting and Clinical Psychology, 51, 215-225. 
Eder, E., Turic, K., Milasowsky, N., Van Adzin, K., \& Hergovich, A. (2011). The relationship between paranormal belief, creationism, intelligent design, and evolution at secondary schools in Vienna (Austria). Science \& Education, 20, 517-534.

Ford, C. L., Wallace, S. P., Newman, S. P., Lee, S. J., \& Cuningham, W. E. (2013). Belief in AIDS-related conspiracy theories and mistrust in the government: relationship with HIV testing among at-risk older adults. The Gerontologist, 53, 973-984.

Francis, L. J., Williams, E., \& Robbins, M. (2010). Personality, conventional Christian belief, and unconventional paranormal belief: a study among teenagers. British Journal of Religious Education, 32, 31-39.

Franz, T. M., \& Green, K. H. (2013). The impact of an interdisciplinary learning community course on pseudoscientific reasoning in first-year science students. Journal of the Scholarship of Teaching and Learning, 13, 90-105.

Frye, B., Alfred, N., \& Campbell, M. (1999). Use of the Watson-Glaser critical thinking appraisal with BSN students. Nursing and Health Care Perspectives, 20, 253-255.

Fulljames, P., Gibson, H. M., \& Francis, L. J. (1991). Creationism, scientism, Christianity, and science: a study in adolescent attitudes. British Educational Research Journal, 17, 171-190.

Gallup, G. H., \& Newport, T. (1991). Belief in paranormal phenomena among adult Americans. The Skeptical Inquirer, 15, 137-146.

Gasparatou, R. (2017). Scientism and scientific thinking. Science \& Education. 26(7-9), 799-812.

Gaston, G. B., \& Alleyne-Green, B. (2013). The impact of African American's beliefs about HIV medical care on treatment adherence: a systematic review and recommendations for interventions. AIDS and Behavior, 17, 31-40.

Glennan, S. (2009). Whose science and whose religion? Reflections on the relations between scientific and religious worldviews. Science \& Education, 18, 797-812.

Gould, S. J. (1997). Non-overlapping magisteria. Natural History, 106, 16-22.

Gross, N., \& Simmons, S. (2007). How religious are America's college and universityprofessors? SSRC Web Forum on the Religious Engagements of American Undergraduates. Available at: http://religion.ssrc. org/reforum/Gross_Simmons.pdf.

Gross, N., \& Simmons, S. (2009). The religiosity of American college and university professors. Sociology of Religion, 70, 101-129.

Guzzetti, B. J. (2000). Learning counter-intuitive science concepts: what have we learned from over a decade of research? Reading and Writing Quarterly, 16, 89-98.

Haack, S. (2007). Defending science within reason: between scientism and cynicism . New York: Prometheus Books.

Hansson, L., \& Lindahl, B. (2010). "I have chosen another way of thinking": students' relations to science with a focus on worldview. Science \& Education, 19, 895-918.

Harraldsson, E., \& Houtkooper, J. (1996). Traditional Christian beliefs, spiritualism, and the paranormal: an Icelandic-American comparison. The International Journal for the Psychology of Religion, 6, 51-64.

Hergovich, A., Schott, R., \& Arendasy, M. (2008). On the relationship between paranormal belief and schizotypy among adolescents. Personality and Individual Differences, 45, 119-125.

Hill, J. P. (2011). Faith and understanding: specifying the impact of higher education on religious belief. Journal for the Scientific Study of Religion, 50, 533-551.

Irwin, H. J. (2000). Belief in the paranormal and a sense of control over life. European Journal of Parapsychology, 15, 68-78.

Irzik, G., \& Nola, R. (2009). Worldviews and their relation to science. Science \& Education, 18, 729-745.

Jolley, D., \& Douglas, K. M. (2014). The social consequences of conspiracism: exposure to conspiracy theories decreases intentions to engage in politics and to reduce one's carbon footprint. British Journal of Psychology, 105, 35-56.

Jones, L., Sciamanna, C., \& Lehman, E. (2010). Are those who use specific complementary and alternative medicine therapies less likely to be immunized? Preventive Medicine, 50, 148-154.

Jr Gauch, H. G. (2009). Science, worldviews, and education. Science \& Education, 18, 667-695.

Kane, M. J., Core, T. J., \& Hunt, R. R. (2010). Bias versus bias: harnessing hindsight to reveal paranormal belief change beyond demand characteristics. Psychonomic Bulletin and Review, 17, 206-212.

Kowalski, P., \& Taylor, A. K. (2009). The effect of refuting misconceptions in the introductory psychology class. Teaching of Psychology, 36, 153-159.

Lacey, H. (2009). The interplay of science activity, worldviews, and value overlooks. Science \& Education, 18, 839-860.

Laudan, L. (1996). Beyond positivism and relativism: theory, method, and evidence. Westview Press 288pp.

Lewandowsky, S., Oberauer, K., \& Gignac, G. E. (2013). NASA faked the moon landing-therefore, (climate) science is a hoax: an anatomy of the motivated rejection of science. Psychological Science, $24,622-633$.

Lenzenweger, M. F., Bennett, M. E., \& Lilenfeld, L. R. (1997). The referential thinking scale as a measure of schozotypy: scale development and initial construct validation. Psychological Assessment, 9, 452-463. 
Lindeman, M., \& Aarnio, K. (2006). Paranormal beliefs: their dimensionality and correlates. European Journal of Personality, 20, 585-602.

Lindeman, M., \& Saher, M. (2007). Vitalism, purpose and superstition. British Journal of Psychology, 98, 33-44.

Lobato, E., Mendoza, J., Sims, V., \& Chin, M. (2014). Examining the relationship between conspiracy theories, paranormal beliefs, and pseudoscience acceptance among a university population. Applied Cognitive Psychology, 28, 617-625.

Loving, C. C. (1991). The scientific theory profile: a philosophy of science model for teachers. Journal of Research in Science Teaching, 28, 823-838.

Mahner, M., \& Bunge, M. (1996). Is religious education compatible with science education? Science \& Education, 5, 101-123.

Manza, L., Hilperts, K., Hindley, L., Marco, C., Santana, A., \& Hawk, M. V. (2010). Exposure to science is not enough: the influence of classroom experiences on belief in paranormal phenomena. Teaching of Psychology, 37, 165-171.

Martin, M. (1994). Pseudoscience, the paranormal, and science education. Science \& Education, 3, 357-371.

Martin-Hansen, L. M. (2008). First-year college students' conflict with religion and science. Science \& Education, 17, 317-357.

Matthews, M. R. (2009). Science, worldviews and education: an introduction. Science \& Education, 18, $641-666$.

McKinnon, A. M. (2003). The religious, the paranormal, and church attendance: a response to Orenstein. Journal for the Scientific Study of Religion, 42, 299-303.

McLaughlin, A. C., \& McGill, A. E. (2017). Explicitly teaching critical thinking skills in a history course. Science \& Education. 26 (1-2), 93-105.

McLean, C. P., \& Miller, N. A. (2010). Changes in critical thinking skills following a course on science and pseudoscience: a quasi-experimental study. Teaching of Psychology, 37, 85-90.

McLeish, J. D. (1984). Children's superstitions: British and Canadian. Canadian Journal of Education, 19, 425-436.

McNally, R. J., Lasko, N. B., Clancy, S. A., Macklin, M. L., Pitman, R. K., \& Orr, S. P. (2004). Psychophysiological responding during script-driven imagery in people reporting abduction by space aliens. Psychological Science, 15, 493-497.

Mencken, F. C., Bader, C. D., \& Stark, R. (2008). Conventional Christian beliefs and experimentation with the paranormal. Review of Religious Research, 50, 194-205.

Mencken, F. C., Bader, C. D., \& Kim, Y. J. (2009). Round trip to hell in a flying saucer: the relationship between conventional Christian and paranormal beliefs in the United States. Sociology of Religion, 70, 65-85.

Meyersburg, C. A., Bogdan, R., Gallo, D. A., \& McNally, R. J. (2009). False memory propensity in people reporting recovered memories of past lives. Journal of Abnormal Psychology, 118, 399-404.

Moreira-dos-Santos, F., \& El-Hani, C. N. (2017). Belief, knowledge, and understanding: how to deal with the relations between different cultural perspectives in classrooms. Science \& Education, 26, 215-245.

Musella, D. (2005). Gallup poll shows that American's belief in the paranormal persists. The Skeptical Inquirer, $29,5$.

Nahin, R. L., Barnes, P. M., Stussman, B. J., \& Bloom, B. (2009). Costs of complimentary and alternative medicine (CAM) and frequency of visits to CAM practitioners: United States 2007. National Health Statistics Reports, 18, 1-14.

Newby, R. W., \& Davis, J. B. (2004). Relationships between locus of control and paranormal beliefs. Psychological Reports, 94, 1261-1266.

Nisbet, M. (1998). New poll points to increase in paranormal belief. The Skeptical Inquirer, 22, 9-12.

Nunnally, J. C., \& Bernstein, I. H. (1994). Psychometric theory (3rd ed.). New York: McGraw Hill.

Oliver, J. E., \& Wood, T. J. (2014a). Conspiracy theories and the paranoid style(s) of mass opinion. American Journal of Political Science, 58, 952-966.

Oliver, J. E., \& Wood, T. J. (2014b). Medical conspiracy theories and health behaviors in the United States. JAMA Internal Medicine, 174, 817-818.

Orenstein, A. (2002). Religion and paranormal belief. Journal for the Scientific Study of Religion, 41, 301-311.

Otis, L. P., \& Alcock, J. E. (1982). Factors affecting extraordinary belief. The Journal of Social Psychology, 118, 77-85.

Padgett, V. R., \& Jorgenson, D. O. (1982). Superstition and economic threat: Germany 1918-1940. Personality and Social Psychology Bulletin, 8, 736-741.

Parnell, J. O. (1988). Measured personality characteristics of persons claiming UFO experiences. Psychotherapy in Private Practice, 6, 159-165.

Parnell, J. O., \& Sprinkle, R. L. (1990). Personality characteristics of persons who claim UFO experiences. Journal of UFO Studies, 2, 45-58.

Peltzer, K. (2003). Magical thinking and paranormal beliefs among secondary and university students in South Africa. Personality and Individual Differences, 35, 1419-1426.

Reimer, S. (2010). Higher education and theological liberalism: revisiting the old issue. Sociology of Religion, 71, $393-408$.

Reiss, M. J. (2009). Imagining the world: the significance of religious worldviews for science education. Science \& Education, 18, 783-796. 
Rice, T. W. (2003). Believe it or not: religious and other paranormal beliefs in the United States. Journal for the Scientific Study of Religion, 42, 95-106.

Rotter, J. B. (1966). Generalized expectancies for internal vs external control of reinforcement. Psychological Monographs, 80(1), (whole no. 609).

Ryan, T. J., Brown, J., Johnson, A., Sanberg, C., \& Schildmier, M. (2004). Science literacy and belief in the paranormal-an empirical test. Skeptic, 10, 12-13.

Sagan, C. (1995). The demon-haunted world: science as a candle in the dark (457pp). New York: Random House.

Sagone, E., \& De Caroli, M. E. (2014). Locus of control and beliefs about superstition and luck in adolescents: what's their relationship? Procedia - Social and Behavioral Sciences, 140, 318-323.

Sandor, M. K., Clark, M., Campbell, D., Rains, A. P., \& Cascio, R. (1998). Evaluating critical thinking skills in a scenario-based community health course. Journal of Community Health Nursing, 15, 21-29.

Scott, J. N., Markert, R. J., \& Dunn, M. M. (1998). Critical thinking: clinical clerkships. Medical Education, 32, 14-18.

Sharps, M. J., Newborg, E., Van Arsdall, S., DeRuiter, J., Hayward, B., \& Alcantar, B. (2010). Paranormal encounters as eyewitness phenomena: psychological determinants of atypical perceptual interpretations. Current Psychology, 29, 320-327.

Shermer, M. (1997). Why people believe weird things: superstition and other confusions of our time. New York: Freeman Publishing 306pp.

Sjödin, U. (2002). The Swedes and the paranormal. Journal of Contemporary Religion, 17, 75-85.

Stark, E. (2012). Enhancing and assessing critical thinking in a psychological research methods course. Teaching of Psychology, 39, 107-112.

Swami, V. (2012). Social psychological origins of conspiracy theories: the case of the Jewish conspiracy theory in Malaysia. Frontiers in Psychology, 3, 280.

Swami, V., Pietschning, J., Stieger, S., \& Voracek, M. (2011). Alien psychology: associations between extraterrestrial beliefs and paranormal ideation, superstitious beliefs, and the big five personality factors. Applied Cognitive Psychology, 25, 647-653.

Swami, V., Voracek, M., Stieger, S., Tran, U. S., \& Furnham, A. (2014). Analytic thinking reduces belief in conspiracy theories. Cognition, 133, 572-585.

Tellegen, A., \& Atkinson, G. (1974). Openness to absorbing and self-altering experiences ("absorption"), a trait related to hypnotic susceptibility. Journal of Abnormal Psychology, 83, 268-277.

Tobacyk, J. (2004). A revised paranormal belief scale. International Journal of Transpersonal Studies, 23, 94 98.

Tobacyk, J., \& Milford, G. (1983). Belief in paranormal phenomena: assessment instrument development and complications for personality functioning. Journal of Personality and Social Psychology, 44, 1029-1037.

Tobacyk, J., \& Pirttilä-Backman, A. M. (1992). Paranormal beliefs and their implications in university students from Finland and the United States. Journal of Cross-Cultural Psychology, 23, 59-76.

Utinans, A., \& Ancane, G. (2014). Belief in the paranormal and modern health worries. SHS Web of Conferences, $10,00048$.

Utinans, A., Ancane, G., Tobacyk, J., Boyraz, G., Livingston, M. M., \& Tobacyk, J. S. (2015). Paranormal beliefs of Latvian college students: a Latvian version of the revised paranormal belief scale. Psychological Reports: Measures and Statistics, 116, 116-126.

Walker, W. R., Hoekstra, S. J., \& Vogl, R. J. (2002). Science education is no guarantee of skepticism. Skeptic, 9 , 24-28.

Wilson, J. A. (2001). Pseudoscientific beliefs among college students. Reports of the National Center for Science Education, 21, 9-13.

Wiseman, R., \& Watt, C. (2004). Measuring superstitious belief: why lucky charms matter. Personality and Individual Differences, 37, 1533-1541.

Woodcock, B. A. (2014). "The scientific method" as myth and ideal. Science \& Education, 23, 2069-2093.

Wyer, K. (2009). U. S. Faculty: Civic engagement, diversity important goals for undergraduate education. Retrieved June 14, 2011, from http://www.heri.ucla.edu/PDFs/press/pr030509-08faculty.pdf. 